\title{
Intrathecal Buprenorphine, Clonidine and Fentanyl as Adjuvants To 0.5\% Hyperbaric Bupivacaine In Lower Abdominal Surgeries: A Prospective, Randomized And Comparative Study.
}

\author{
${ }^{1}$ Krishnakumar Srinivasagam, ${ }^{2}$ Ayyavu Chandrasekaran, ${ }^{3}$ Nanthaprabu.M \\ ${ }^{I}$ Professor of Anesthesiology, Kilpauk Medical College Hospital, Chennai, Affliated to the Tamilnadu \\ Dr.M.G.R Medical University \\ ${ }^{2}$ Professor of Anesthesiology, Kilpauk Medical College Hospital, Chennai, Affliated to the Tamilnadu \\ Dr.M.G.R Medical University \\ ${ }^{3}$ Assistant Professor of Anesthesiology, Kilpauk Medical College Hospital, Chennai, Affliated to the Tamilnadu \\ Dr.M.G.R Medical University
}

\begin{abstract}
Background: Among all the spinal adjuvants, clonidine, an alpha-2 agonist has the ability to alleviate both the somatic and visceral pain and is more potent at spinal site, favoring its neuraxial administration.

Objective: This study was done to compare the onset and duration of sensory and motor blocks, duration of analgesia, haemodynamic and adverse effects of Clonidine, buprenorhine and fentanyl used intrathecally with hyperbaric $0.5 \%$ bupuvacaine.

Settings \& Design: This prospective, randomized and comparative study included 90 ASA class 1 \& 2 patients undergoing lower abdominal surgeries under spinal anesthesia after approval from hospital ethics committee with written informed consent of patients.

Materials And Methods: Patients were randomly allocated into three groups $(n=30)$ and received 50 $\mu \mathrm{g}$ of clonidine, $25 \mu \mathrm{g}$ of fentanyl and $75 \mu \mathrm{g}$ of buprenorphine respectively in group $B C, B F$ and $B B$ as adjuvants to $15 \mathrm{mg}$ of $0.5 \%$ hyperbaric bupivacaine $(3.0 \mathrm{ml})$. The onset time and duration of sensory and motor block, duration of analgesia, haemodynamic changes and side effects were recorded.

Results: The onset time of motor block and durations of sensory, motor blockade and analgesia were prolonged in-group $B C$ as compared to group $B F$ and $B B(P<.001)$. There was no significant difference in the onset time of sensory block in three groups (P>.05). Group BC had lower heart rate and mean blood pressure and higher sedation score.
\end{abstract}

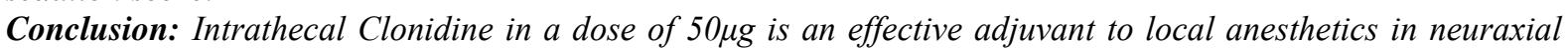
blocks despite mild sedation and haemodynamic variations.

Keywords: a2-adrenoceptor agonist, Bupivacaine, Buprenorphine, Clonidine, Fentanyl.

\section{Introduction}

Spinal anesthesia is the most commonly used technique for lower abdominal and surgeries. Of all adjuvants, opioids and Clonidine are continuously gaining popularity for their desirable effects and better profile of adverse effects than others. Opioids and local anesthetics administered together intrathecally are known to have synergistic analgesic effects, whereas Clonidine, an alpha-2 receptor agonist has emerged out with its desirable anesthetic properties. It role is being explored in neuraxial blocks as an adjuvant to local anesthetics for reducing their requirements, improving haemodynamic stability and providing analgesia.[1-3]

When local anesthetic, bupivacaine is combined with Intrathecal Clonidine, complete surgical anesthesia could be obtained along with relief from somatic as well as visceral pain both intra and post operatively with fewer side effects.[3-6] This study was conducted to evaluate onset and duration of sensory and motor block, duration of analgesia, haemodynamic and adverse effects of fentanyl, buprenorphine and Clonidine given intrathecally with hyperbaric $0.5 \%$ bupivacaine.

\section{Materials \& Methods}

Ninety patients aged 20-60 years, of American Society of Anesthe-siologists (ASA) grade 1 and 2, scheduled for lower abdominal surgeries lasting not more than three hours were included in the study. After obtaining approval from the institutional ethics committee and ascertaining selection criteria, informed valid consent was obtained for participation in the study. Exclusion criteria were patient's refusal, coagulation abnormalities, allergy to any drug being used, pre-existing severe bradycardia or ejection fraction $<30 \%$, hypovolemia or hypotension, arrhythmias, or cardiac block, raised intracranial pressure, head injury, bronchial asthma, caesarean section or any other contraindication to spinal anesthesia. 
Preoperative evaluation was carried out in all patients with detailed history, general physical examination including height and weight, evidence of any special deformity or any neurological disease and mental status of the patient. Pulse rate, blood pressure, respiratory rate and oxygen saturation in room air were noted and systemic examination was performed. The patients were randomly divided in three groups of thirty each using a computer random number sequence.

GROUP BC $-3.0 \mathrm{ml}$ of $0.5 \%$ of hyperbaric bupivacaine $(15 \mathrm{mg})+50 \mu \mathrm{g}(0.33 \mathrm{ml})$ of Clonidine $+(0.17 \mathrm{ml}$ normal saline) $=3.5 \mathrm{ml}$.

GROUP BF $-3.0 \mathrm{ml}$ of $0.5 \%$ hyperbaric bupivacaine $(15 \mathrm{mg})+25 \mu \mathrm{g}(0.5 \mathrm{ml})$ fentanyl $=3.5 \mathrm{ml}$.

GROUP BB $-3.0 \mathrm{ml}$ of bupivacaine heavy $0.5 \%(15 \mathrm{mg})+$ buprenorphine $75 \mu \mathrm{g}(0.25 \mathrm{ml})+$ normal saline $(0.25 \mathrm{ml})=3.5 \mathrm{ml}$.

The total volume of solution in all the groups was $3.5 \mathrm{ml}$ and the drug solution was prepared by an anesthesiologist not involved in the study. All patients were familiarized with visual analogue scale (VAS). A preoperative fasting of 6 hour was confirmed and baseline heart rate and blood pressure were noted. Glycopyrrolate $0.2 \mathrm{mg}$ was administered intramuscularly to all patients, 30 minutes before procedure. In the operation theatre, an intravenous line was secured and preloading was done with Lactated Ringer's solution at the rate of 10 to $15 \mathrm{ml} / \mathrm{kg}$. No sedatives or analgesics were administered preoperatively. Patient monitoring included non-invasive blood pressure, pulse oximetry and three lead electrocardiograms.

Subarachnoid block was performed in sitting position with midline approach under strict aseptic precautions using 25 Gauzge quincke needle. The loaded drug was injected over 10 to 15 seconds, once free flow of cerebrospinal fluid was confirmed. The time at which the injection completed was considered zero time of the study and all the measurements were recorded from this point. Patients were immediately placed in supine position supporting the head and shoulders. Oxygen was given with the face mask at flow rate of $4 \mathrm{l} / \mathrm{min}$.

The highest level of sensory block was sensed by pinprick method in caudal to cephalic direction every two minute, after the procedure of subarachnoid block was complete and the time taken to achieve absence of pinprick response at T 10 level in midclavicular line was taken as onset of sensory block. Motor block was assessed by modified Bromage scale7 (Bromage 0: able to move hip, knee and ankle, Bromage 1: not able to move hip but able to move knee and ankle, Bromage 2: unable to move hip and knee but can move ankle, Bromage 3: unable to move any). Time taken to reach Bromage 3 was noted and was considered the onset of motor block. Intraoperative sedation was tested on subjective sedation scale as described by Wilson et al8: Grade 1: calm and oriented, Grade 2: drowsy, Grade 3: arousable to verbal command, Grade 4: arousable to mild physical stimulation, Grade 5: unarousable.

Satisfactory block was defined as a sensory level of T 10 and modified Bromage score of three. Duration of sensory block was defined from completion of drug injection to the re-appearance of response to pinprick at L-1 level. Duration of motor block was recorded as time from injection of drug into the subarachnoid space to achieve Bromage-0. Both the durations were noted. Duration of surgery was also recorded. Postoperative pain was assessed by visual analogue scale (VAS) using a plain scale measuring $10 \mathrm{cms}$ with 1 mm markings, in which 10 corresponded with most extreme pain and point 0 with no pain at all. Duration of analgesia was taken from the time of intrathecal drug administration to the time when patient, first complained of pain. At that point the study was terminated with respect to analgesia and injection paracetamol $15 \mathrm{mg} / \mathrm{kg}$ was given. Postoperatively the hemodynamic variables and oxygen saturation were recorded until complete recovery of the patients from anesthesia.

Statistical analysis was done using Statistical Package for Social Science (SPSS 20.0 evaluation version). Data were expressed as means and standard deviation (SD). For categorical data chi-square test was used with $\mathrm{P}$ value reported at the $95 \%$ confidence interval (CI). Continuous data were compared using analysis of variance (ANNOVA). If P value was significant, then Tukey's honestly significant difference (HSD) posthoc test was applied to see the significance between each pair of groups.

\section{Results}

The three groups were comparable with respect to age, weight, height, ASA physical status and duration of surgery [Table-1]. The characteristics of the subarachnoid blocks in three groups with inter-group comparison are shown in table-2 (Table-2). There was no significant difference in the onset time of sensory block in three groups ( $p>05$ ), although Clonidine group had fastest onset. There was significant difference in the onset time of motor block, duration of sensory and motor block and duration of analgesia in all the groups $(\mathrm{p}<.001)$. There was significant difference in VAS score at 4 and $6 \mathrm{hr}$ in all the groups, with lowest score in group BC. Subjective sedation scores also differed significantly in all the groups with a maximum score in group BC followed by BB and BF. Heart rate (Figure-1) and mean blood pressure (Figure-2) were also found to 
Intrathecal Buprenorphine, Clonidine and Fentanyl As Adjuvants To 0.5\% Hyperbaric Bupivacaine...

be lower in group $\mathrm{BC}$ as compared to group $\mathrm{BF}$ and $\mathrm{BB}$. Bradycardia and hypotension were found more in group $\mathrm{BC}$, whereas nausea, vomiting and itching were found in group $\mathrm{BF}$ and $\mathrm{BB}$.

Table 1: Demographic Profile

\begin{tabular}{|c|c|c|c|c|c|c|}
\hline Variable & Group BC & Group BF & \multicolumn{2}{|l|}{ Group BB } & & \\
\hline Age (years) & $39.33 \pm 13.46$ & $41.17 \pm 13.22$ & \multicolumn{2}{|l|}{$37.27 \pm 14.50$} & & \\
\hline Height $(\mathrm{cm})$ & $153.20 \pm 3.33$ & $155.10 \pm 2.57$ & \multicolumn{2}{|l|}{$154.35 \pm 4.30$} & & \\
\hline Weight $(\mathrm{kg})$ & $56.60 \pm 7.23$ & $58.23 \pm 5.21$ & \multicolumn{2}{|l|}{$57.42 \pm 6.30$} & & \\
\hline ASA $1 / 2$ & $16 / 14$ & $15 / 15$ & \multicolumn{2}{|l|}{$13 / 17$} & & \\
\hline $\operatorname{Sex}(\mathrm{M} / \mathrm{F})$ & $16 / 14$ & $15 / 15$ & \multicolumn{2}{|l|}{$17 / 13$} & & \\
\hline $\begin{array}{ll}\text { Duration } & \text { of } \\
\text { surgery }(\min )\end{array}$ & $148 \pm 20.53$ & $147 \pm 12.46$ & \multicolumn{2}{|l|}{$149 \pm 18.65$} & & \\
\hline Variable & Group BC & Group BF & Group BB & P Value BC/BF & P Value BC/BB & P Value BF/BB \\
\hline $\begin{array}{l}\text { Onset of sensory } \\
\text { block (sec.) }\end{array}$ & $463.8 \pm 54.42$ & $477.6 \pm 55.2$ & $477.6 \pm 61.8$ & $.614 f$ & $.614 f$ & $1.000 f$ \\
\hline $\begin{array}{l}\text { Onset of motor } \\
\text { block (sec.) }\end{array}$ & $142.66 \pm 39.99$ & $220 \pm 52.06$ & $274 \pm 56.11$ & $.000 *$ & $.000^{*}$ & $.000 *$ \\
\hline $\begin{array}{l}\text { Duration } \\
\text { sensory } \\
\text { block(min.) }\end{array}$ & $306.67 \pm 60.47$ & $174.33 \pm 23.44$ & $267 \pm 30.18$ & $.000 *$ & $.018^{*}$ & $.000 *$ \\
\hline $\begin{array}{l}\text { Duration of motor } \\
\text { block(min.) }\end{array}$ & $254.67 \pm 72.05$ & $151.27 \pm 12.02$ & $222.66 \pm 24.34$ & $.000 *$ & $.001 *$ & $.000 *$ \\
\hline $\begin{array}{l}\text { Duration of } \\
\text { analgesia (min.) }\end{array}$ & $353.19 \pm 7.69$ & $195.83 \pm 7.30$ & $294.00 \pm 17.93$ & $.000^{*}$ & $.000^{*}$ & $.000 *$ \\
\hline
\end{tabular}
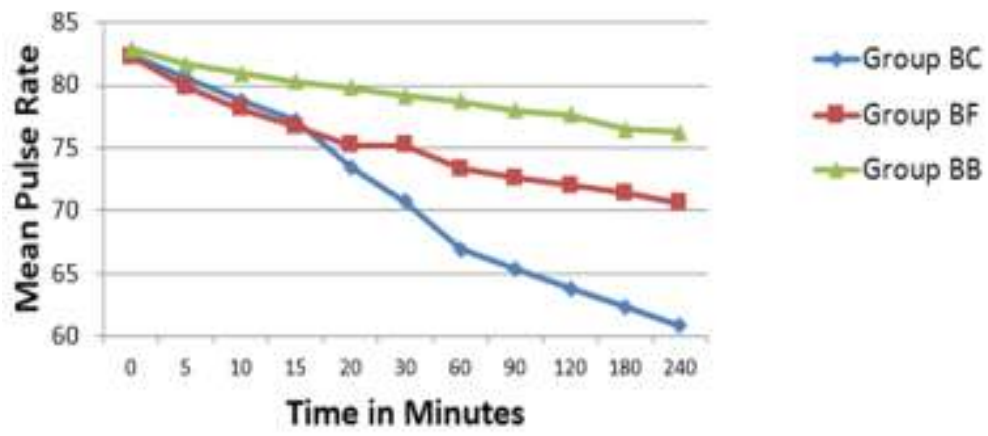

Fig. 1: Variations in Pulse Rate

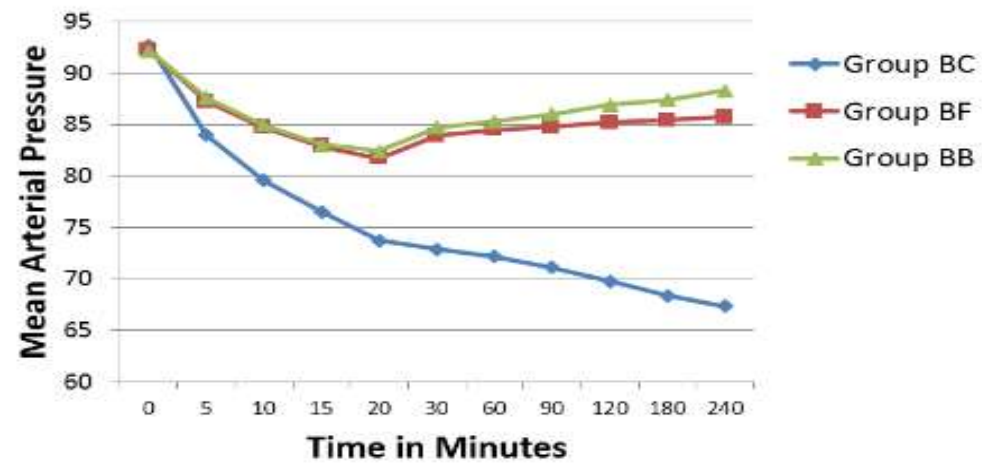

Fig. 2: Variations in Mean Arterial Pressure

\section{Discussion}

Antinociceptive action of Clonidine exists for somatic and visceral pain.[ 9,10] Clinical efficacy of Intrathecal Clonidine to relieve visceral pain in well-established[11-12] but Clonidine is also associated with few side effects like bradycardia, hypotension and dry mouth. So, $50 \mu \mathrm{g}$ dose of Clonidine was chosen in our study, as higher doses (150ug) are also associated with significant risk of hypotension as reported by Chiari et, al.[13] 
Clonidine is a selective partial agonist for $\alpha 2$ adrenergic receptors and it is the most studied drug used for neuraxial anesthesia.[14] It is more potent after neuraxial than systemic administration indicating spinal site of action and favoring neuraxial administration.[15] It is moderately lipid soluble, easily penetrates the blood brain barrier leading to spinal and supra spinal receptor binding and thus provides effective and long lasting post-operative analgesia. Recently, Clonidine has also been shown to increase acetylcholine (Ach) levels in lumbar cerebrospinal fluid, as cholinergic activation imparts analgesia.[15] It may also cause local vasoconstriction.[15] Intrathecal $\alpha 2$ agonists are found to have antinociceptive action for both somatic and visceral pain.[16]

Fentanyl is a lipophilic $\mu$ receptor agonist opiod. Intrathecally It exerts its effect by combining with opioid receptor in the dorsal horn of spinal cord and may have a supraspinal spread and action. The effectiveness of Intrathecal opioids depends on their bioavailability,[17] so opioids can provide good perioperative analgesia. Reuben et al[18] used different doses $(5,10,20,40,50 \mu \mathrm{g})$ of fentanyl in their study and found that even $20 \mu \mathrm{g}$ of fentanyl in combination of $0.5 \%$ of bupivacaine gave good amount of analgesia. So, we have used $25 \mu \mathrm{g}$ of fentanyl in our study.

Buprenorphine is another opioid which increases sensory block without affecting motor block and haemodynamic[19] it also has high lipid solubility and highest affinity for opiate receptors [20,21,22]. As suggested by Capogna et al,[21] duration of analgesia is dose dependent and it was found to increase up to 294.0 \pm 17.93 minutes with buprenorphine in our study, which is less than 475 minutes and 430 minutes as stated by Shaikh and kiran et al[23] and capogna et al,[22] respectively.

There was no significant difference in onset time of sensory block in three groups $(463.8 \pm 54.42$ seconds, 477.6 \pm 55.2 seconds, and $477.6 \pm 61.8$ seconds in group $\mathrm{BC}, \mathrm{BF}$ and $\mathrm{BB}$ respectively) $(\mathrm{P}>0.5)$. This result was supported by studies done by Singh et al[24] and Strebel et al,[25] where they concluded that fentanyl as well as Clonidine does not alter the onset of sensory block, whereas onset of sensory block in BB group did not match to a study done by Dixit et al[26] in caesarean sections in which it was significantly shortened to $1.85 \pm 1.39$ min with the addition of buprenorphine to $0.5 \%$ hyperbaric bupivacaine $(5.35 \pm 1.79$ minutes.)

The difference in mean onset of motor block (Bromage 3) was statistically significant in all three groups being $142.66 \pm 33.99$ seconds, $222 \pm 52.06$ seconds and $274 \pm 56.11$ seconds in group BC, BF and BB respectively ( $\mathrm{p}$ value<.001). It was lower than onset time for sensory block in all the groups of our study, probably because onset of sensory block was taken as a time for its spread up to T10 level. The value of $274 \pm 56.11$ seconds achieved with $75 \mu \mathrm{g}$ of buprenorphine in our study was comparable to 198 seconds achieved with $60 \mu \mathrm{g}$ of buprenorphine in a study done by Gupta M[27] et al.

The time taken for regression of sensory block to L-1 was statistically significant being $306.67 \pm 60.47$ minute, $267 \pm 30.18$ minute and $174.33 \pm 23.44$ minute in group BC, BB and BF respectively $(\mathrm{p}<.001)$. The duration of sensory block in group BC is supported by study of Elia et al, [28] who concluded that time taken for two segment regression was prolonged with 150 microgram dose of Clonidine although associated with hypotension. This value of $306.67 \pm 60.47 \mathrm{sec}$. was again supported by a dose response study done by Strebel et al, [25] where the time for L1 regression was $325 \pm 69 \mathrm{~min}$ with $75 \mu \mathrm{g}$ Clonidine, Which was slightly higher than the dose used in group BC of our study. The mean time of sensory regression to L-1 in group BF i.e. $174.33 \pm 23.44 \mathrm{~min}$ is slightly lower to the regression time to $\mathrm{S} 1$ level i.e. $179 \pm 47 \mathrm{~min}$ in a study done by Ghanem S M et al. [29] The mean time to regression of sensory block to L1 in group BB was $267 \pm 30.18$ with $75 \mu \mathrm{g}$ of buprenorphine and is comparable to $225 \pm 64.49$ minutes with $60 \mu \mathrm{g}$ of buprenorphine as found in study

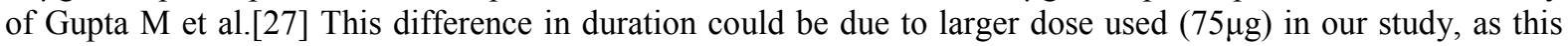
effect is dose dependent with opioids. There was significant difference in the durations of motor Block in all three groups. $(\mathrm{p}<.001)$.

The duration of motor block in group BF (151.27 $\pm 12.02 \mathrm{~min})$ shows that fentanyl does not prolong it as supported by the study of Singh et al [24] however, Clonidine significantly prolongs the duration of motor block up to 254.67 \pm 72.05 minutes as supported by the studies of Elia et al[28] and Jain et al.[29] However this was in contrast to the study of kabbachi et al [30], who concluded that the addition of $2 \mu \mathrm{g} / \mathrm{kg}$ Clonidine (= $100 \mu \mathrm{g}$ ) to hyperbaric $0.5 \%$ bubivcaine does not prolong the duration of motor block. The duration of motor block in group BB $(222.66 \pm 24.34 \mathrm{~min})$ was comparable to $205.17 \pm 63.0$ minutes achieved with $60 \mu \mathrm{g}$ of buprenorphine, in a study done by Gupta M. et al.[27]

The difference in duration of analgesia was also significant in all the 3 groups $(\mathrm{p}<.001)$ being longest in group BC (353.19 $\pm 7.69 \mathrm{~min})$ and lowest in group BF (195.83 $\pm 7.30 \mathrm{~min})$. The durations of analgesia in group BC and group BF in our study were comparable to $386.8 \pm 13.56 \mathrm{~min}$. with clonidine $60 \mu \mathrm{g}$ and $289.83 \pm 15.4 \mathrm{~min}$. with fentanyl $50 \mu \mathrm{g}$, respectively in a study done by Strebel et al,(25) The duration of analgesia with buprenorphine in our study i.e. $294 \pm 17.93$ minutes was quite comparable to $289.66 \pm 64.94$ minutes as in the study done by Gupta $\mathrm{M}$ et al. [27]

Haemodynamic variations were more pronounced in group $\mathrm{BC}$ as compared to group $\mathrm{BB}$ and $\mathrm{BF}$. Respiratory depression also did not occur in any of the group. The decrease in blood pressure in group BC was 
supported by the study of Elia et al[28] who reported that there were more episodes of hypotension with $150 \mu \mathrm{g}$ of Clonidine. This is in contrast to the study done by strebel et al[25] that relative hemodynamic stability was maintained with $150 \mu \mathrm{g}$ of Clonidine in combination with $0.5 \%$ hyperbaric bupuvacaine. VAS score was also significantly lower in group BC than in group BB and BF as supported by the study of Jain et al.[29] and Grandhe et al.[31] Sedation score in group BC was higher than in group BF and group BB. Absence of control group to compare the effects of drugs separately has been the limitation of our study.

\section{Conclusion}

It can be concluded that although Intrathecal Clonidine $(50 \mu \mathrm{g})$ is associated with mild hemodynamic instability and sedation, it provides quicker onset and prolonged duration of sensory and motor blocks simultaneously increasing the duration of analgesia when compared to fentanyl $(50 \mu \mathrm{g})$ and buprenorphine $(75 \mu \mathrm{g})$ and can be used as optimal dose as an Intrathecal adjuvant.

\section{References}

[1]. Bloor BC, Flacke WE. Reduction in halothane requirement by Clonidine, an alpha-adrenergic agonist. Anesth Analg 1982; 67; 7415.

[2]. Ghignone M, Calvillo O, Quintine L. Anesthesia and hypertension; the effects of Clonidine on perioperative haemodynamics and halothane requirements. Anesthesiology 1987; 67(1); 3-10.

[3]. Gordh T. Epidural Clonidine for treatment of postoperative pain relief after thoracotomy. A double-blind placebo-controlled study. Acta Anesthesiol Scand 1988; 32(8): 702-9.

[4]. Kirno K, Lundin S, Elam M. Epidural Clonidine depresses sympathetic nerve activity in humans by supraspinal mechanism. Anaesthesiology 78(6): 10217.

[5]. Mendez R, Eisenach JC, Kashtan k. Epidural Clonidine analgesia after caesarean section. Anaesthesiology 1990; 73(5); 842-52.

[6]. Motsch J, Graber E, Ludwig K. Addition of Clonidine enhances postoperative analgesia from epidural morphine: a double-blind study. Anaesthesiology 1990; 73; 1066-73.

[7]. Bromage PR. A comparison of the hydrochloride and carbon dioxide salts of lidocaine and prilocaine in epidural analgesia. Acta Anaesthesiol Scand Suppl. 1965; 16: 55-69.[PubMed]

[8]. Wilson E, David A, Mackenzie N, Grant IS. Sedation during spinal anaesthesia: Comparison of propofol and midazolam. Br J Aaesth 1990; 64: 48-52.

[9]. Danzebrink RM, Gebhart GF. Antinociceptive effect of intrathecal adrenoceptor agonists in a rat model of visceral nociception. J Pharmacol Exp Ther 1990; 25(3): 698-705.

[10]. Harada Y, Nishioka K, Kitahata LM. Contrasting actions of intrathecal morphine or encephalin or intravenous U50, 488H on the visceromotor response to colorectal distension in rat. Anaesthesiology 1995; 83; 336-43.

[11]. Hunt CO, Naulty JS, Bader AM. Perioperative analgesia with subarachnoid fentanyl-bupivacaine for caesarean delivery. Anesthesiology 1989; 71; 535-40.

[12]. Coutney MA, Bader AM, Hartwell. Perioperative analgesia with subarachnoid sufentanil administration. Reg Anaesth 1992; 17; 274-8.

[13]. Chiari AZ, Lorber C, Eisenach JC, Wildling E, Krenn C, Zavrsky A. Analgesia and haemodynamic effects of intrathecal Clonidine as a sole agent during first stage of labour: a dose-response study. Anaesthesiology 1999; 91: 388-96.

[14]. Maze M, Tranquilli W. Alpha-2 adrenoceptor agonists: defining the role in clinical anesthesia. Anaesthesiology 1991; 74(3): 581605 .

[15]. Eisenach JC, De Kock M, Klimscha W. Alpha-2-adrenergic agonists for regional anesthesia. A clinical review of Clonidine (198485). Anaesthesiology 1996; 85(3): 655-74.

[16]. Al-Ghanem SM, Masood IM, Al-Mustafa MM, Al-Zaben KR, Qudaisat IY, Quatawneh AM. Effect of adding dexmedetomidine versus fentanyl to intrathecal bupivacaine to spinal block characteristics in gynecological procedures. A double-blind controlled study. Am J Appl Sci 2009; 6: 882-7?

[17]. Justins DM, Francis D, Houlton PG, Reynolds F. A controlled trial of extradural fentanyl in labour. Br J Anaesth.1982; 54 : $409-14$.

[18]. Reuben SS, Dunn SM, Duprat KM, O'Sullivan P. An intrathecal fentanyl dose-response study in lower extremity revascularization procedures. Anaesthesiology.1994; 81(6): 1371-5.

[19]. Saxena AK, Arva S. Current concepts in neuraxial administration of opioids and non-opioids: An overview and future perspective. IJA 2004; 48: 13-24.

[20]. Lanz E, Suke G, Theiss D, Glocke MH. Epidural buprenorphine: a double-blind study of postoperative analgesia and side effects. Anesth Analg 1984; 63: 593-98.

[21]. Capogna G, Celleno D. Spinal buprenorphine for postoperative analgesia after caesarean section. Acta Anaesthesiol Scand.1989; $33: 236-238$.

[22]. Capogna G, Celleno D. Intrathecal buprenorphine for postoperative analgesia in the elderly patients. Anaesthesia 1988; 48:128-30.

[23]. Shaikh SI, Kiran M. Intrathecal buprenorphine for postoperative analgesia: A prospective randomized double blind study. J Anaesth Clin Pharmacol.2010; 26:35-8.

[24]. Singh H, Yang J, Thorton K, Adolf H. Study on the effects of intrathecal fentanyl on the onset and duration of hyperbaric bupivacaine. Can J Anaesth.1995; 42(11): 987-91.

[25]. Strebel S, Gurzeler JA, Schneider MC, Aeschbach A, Kindler CH. Small dose intrathecal Clonidine and isobaric bupivacaine for orthopedic surgery: a dose-response study. Anaesth Analg 2004; 99: 1231-8.

[26]. Dixit S. Postoperative analgesia after caesarean section: An experience with intrathecal buprenorphine. IJA 2007; 51(6): 515-18.

[27]. Gupta M, Shailaja S, Hegde KS. Comparison of intrathecal dexmedetomidine with buprenorphine as adjuvant to bupivacaine in spinal anesthesia. J Clin Diagn Res. 2014; 8(2): 114-17.

[28]. Elia N, Culebras X, Mazza C, Schiffner E, Tramer MR. Clonidine as an adjuvant to intrathecal local anesthetics for surgery: Systematic review of randomized trials. Reg Anaesth Pain Med.2008; 33(2); 159-67.

[29]. Jain PN, Gehdoo RP, Priya V. Study of intrathecal Clonidine for postoperative pain relief. Indpain 2003; $17(2)$ : $1233-36$.

[30]. Kabbachi O, Ben Rajeb A, Mebazza M, Sifi H, Jelel C. Spinal anesthesia in children: Comparative study of hyperbaric bupivacaine with or without Clonidine. Br J Anaesth 2006; 33(2): 159-67. 
Intrathecal Buprenorphine, Clonidine and Fentanyl As Adjuvants To 0.5\% Hyperbaric Bupivacaine...

[31]. Grandhe RP, Wig J, Yaddanapudi LN. Evaluation of bupivacaine-Clonidine combination for unilateral spinal anesthesia in lower limb orthopedic surgery. J Anaesthesiol Clin Pharmacol 2008; 24(2): 155-8. 